\title{
The Liar Paradox
}

\author{
Kuang-Ming Wu \\ University of Wisconsin-Oshkosh, Oshkosh, USA \\ Email: Kmwu2002@yahoo.com
}

Received 28 January 2015; accepted 13 April 2015; published 14 April 2015

Copyright (C) 2015 by author and Scientific Research Publishing Inc.

This work is licensed under the Creative Commons Attribution International License (CC BY).

http://creativecommons.org/licenses/by/4.0/

c) (i) Open Access

\section{Abstract}

This essay delivers a serious message on life, at the core of reasoning, to wit, "I am a liar" selfdestructive infests reasoning to undermine it to fill life with oxymora, then proposes a singing way out in music. This essay is naturally divided into three sections: one, how self-destructive the liar paradox is life-ubiquitous; two, the liar paradox as basic to logic and philosophy; and three, how to deal with the liar paradox in snake-charming, in "Tying." In short, these pages say that "I am a liar" self-denies to self-destroy, to demolish the structure of living (Section 1) and reasoning (Section 2). Such self-demolition must be snake-charmed into deeply singing life and reasoning (Section 3 ).

\section{Keywords}

Liar Paradox, Reasoning, Play, Musical Beauty

\section{Introduction}

This essay has a sharp message on life at the core of reasoning, that the liar paradox self-destructs to infest daily life and reasoning to undermine them all, and then proposes music to sing out of the crisis. All this is said in three sections: one, how self-destructive the liar paradox is; two, this paradox as basic to logic and philosophy; and three, dealing with the paradox in snake-charming, in "Tying." All this says that "I am a liar" self-denies to self-destroy, to demolish the structure of living (Section 1) and reasoning (Section 2). Such self-demolition must be snake-charmed into singing life and reasoning (Section 3).

\subsection{One: How Self-Destructive the Liar Paradox Is}

The liar paradox, "I am a liar," has been with us since ancient Greece, and many thinkers in history have been so much worried about it, unable to "solve" it (Sorensen, 2003). But the radical poison of this paradox is not elucidated till this essay comes. "I am a liar" self-denies to self-destroy, to demolish living-structure and reasoning-structure. Let us explain the self-liar as self-denying self-destructive.

The same "I am a liar" proves both that, taken as valid, it is invalid, and that, taken as invalid, it is valid: "I 
am a liar" is "the liar paradox." Paradox is an internal inter-opposition, a unity self-undermining. "Internal” refers to itself; so, "paradox" is a self-referred contradiction, existing as self-demolishing, as self-smashing (para-) reasoning (-dox). Paradox is opposites inter-demolishing inter-composing, an unstable unity typified in the liar paradox. Let us now go slowly, beginning at the existential base of the "I" in any assertion.

Reviews, evaluations, and judgments of things, matters, and persons are routinely done on things other than the evaluator. But when I certify my own trustworthiness, I must confess how truthful I am, even declare it under oath. Now, if the confession turns self-negating, "I am a fake," it declares my non-existence while declaration shows my existence. Such self-negating declaration is impossible, because it destroys itself. Let me explain further.

Any declaration assumes, certifies, and affirms the existence of the declarer its subject, and yet "I am a fake" denies the declarer (the assumption of the declaration); "I am a fake" impossibly denies my existence that must be affirmed to declare it. Thus, "I am a fake" self-destroys; the statement exists and cannot exist. Similarly, one side of a paper-note says "What is said on the other side is true," and its another side says, "What is said on the other side is false," and we cannot settle in the "true"-side or the "false"-side. Both these examples are of logical cul-de-sac, called "paradoxes."

"I am a fake" is dramatized in "I am a liar." "I am a liar" self-lies to self-deny to self-oppose, cognitively and existentially. Self-denial assumes and affirms that the denier exists, and yet self-lying self-denies, and so "I am a liar" cognitively both affirms and rejects oneself. In "I am a liar," the liar oneself is existentially assumed as in any assertion, and yet here the liar denies herself, to self-reject to self-destroy. The self-liar is then in internal inter-opposition, in an impossible dilemma, ever unsettling.

Let us see "I am a liar" from its outside. If we take "I am a liar" as true, we take that she says truthfully, so what she says, "I am a liar," is false; she is no liar as she told us she is. But if we take "I am a liar" as false, we take that she says falsely, and so what she says, "I am a liar," is true. Taken as true, her saying is false; taken as false, her saying is true. and so, the saying destroys the self-liar.

Now, we find such self-liars so abundant daily, as these examples show. Hannah Arendt, a Jewish scholar, judges that no single Jew rose up against the Nazis (Arendt, 1963). Her life (1906-1975) was lived within the Nazi era (1919-1945), so, she is a Jew she accuses of not rising up against the Nazis; her accusation self-accuses, as "I am a liar" self-lies. J. Robert Oppenheimer and Andrei D. Sakharov built atomic weaponry, and then passionately advocated its abolition, and so both were taken as traitors; they turned infamous because they tried to abolish the arsenal they built; it is to tell a lie to oneself. "Their abolition effort was due to their horror at the result, not out of their development itself.” This objection may have as much force as a shooter's who says that the bullet killed, not he.

The great Zen master Dr. Suzuki names himself, “Big Inept 大拙,” as a liar lies to himself; Zen Buddhism is the liar paradox writ ridiculous (Barrett, 1956)! Christianity self-defeats on the cross that is actually God's victory, all for us all, not for God yet all this is for God of Love. Here is the liar paradox three times; one, defeat is victory, two, God did it for us not for God, yet, three, what God did it for us is for God who is love; all these acts self-deny as self-liar self-lies. In the Beyond, our reason curls back on itself self-lying way, as "nonsense” (Wu, 2012).

As said before, a shirt says "Fake," to wit, "I am a fake," as "I am a liar" denying (fake) what is affirmed (declaring establishes oneself as no-fake). A paper note says, "The reverse says truth," and says on its reverse, "The reverse says falsehood." Each side negates the other for the paper to self-negate, as "I am a liar" selfnegates. We laugh, but they are not senseless, not occasional. Usual reasoning is powerless, as they corrode reason from inside. Besides, they forever bother us as gadflies worse than Socrates, who still follows the usual reasoning process.

Thus, the liar paradox consists in four features, each internally opposed. One, the paradox has opposites, affirmative and negative, valid and invalid. Two, these opposites bite one into the other; taking one involves taking the other. Three, such inter-biting composes a unity of self-lying, "I am a liar." Four, and yet this unity is so internally opposed as to be a unity self-corroding.

Internal opposition composes self-referred destruction (para-) of reasoning (-dox); this is "one paradox" against-itself. "Lying” is negation; "self-lying” is self-negation, a unity self-destroying. The self-liar paradox is self-opposing self-destroying in one paradox self-corroding! Pace Hegel, the liar paradox is thesis in antithesis into anti-synthesis self-destructive, with its "logic" twisted beyond self-standing; its dynamics is self-demise. The self-liar paradox is one unity asunder, a synthesis self-opposed. 
In Old Testament, Ecclesiastes proved from experience the futility of experience (Scott, 1965). Demonstrating a thesis with $\mathrm{E}$ proves $\mathrm{E}$ not-futile; if the thesis says that $\mathrm{E}$ is futile, this demonstration repeats the liar paradox, for the thesis destroys the base of its proof, as the liar paradox self-lies; both self-demolish. Proof is philosophical; experience is actual. General deliberation of Ecclesiastes at the boundary of philosophy and actuality proved experience futile with experience; experiential proof proves experience not futile, but here it proves experience futile, exactly as the self-liar self-lies to self-disprove.

"I am a liar" tells a lie to the liar and others, self-corroding pervading; it must be turned around into "woe and weal inter-leaning inter-lurking” (Lao Tzu 58), inter-killing into inter-birthing. Alfred Nobel invented dynamite to earn the name "merchant of death" but, being a pacifist, he invested his earnings in the Nobel Prizes for world peace. Self-poison of the self-liar is here charmed to dance peace, as Section 3 details.

\subsection{Two: The Liar Paradox as Basic to Logic and Philosophy}

"Your examples above, thinker Arendt, scientists Oppenheimer and Sakharov, and master Suzuki, are all actual cases of self-lying. Apodictic necessity of mathematics never lies, never to itself.” You are wrong, my friend! Within thinking itself, the liar paradox is busy at work. We first see self-liar in mathematical "logic," and then see self-liar in "philosophy," comprehensive thinking.

Mathematics is full of illogical stuff, such as one divided by infinity. More seriously and extensively, the crisis of a self-liar is at the center of mathematics apodictic necessity all-logical. The famous mathematical logician Kurt Gödel (Dawson Jr., 1997; Kline, 1980) has conclusively proved, alone, that every proof must be proved not-alone but proved by other proofs (Dawson Jr., 1997; Kline, 1980). But, to my knowledge, no one has realized that Gödel himself with his proof is bankrupt in the liar paradox way, much less that he perpetrated such bankruptcy as a joke in long-face.

Taking his proving process as valid, his "proof" is invalid, for he proved alone the thesis that "proof cannot be proved alone," which is just proved invalid by his solitary proving process. But, taking his proving invalid, his "proof" is valid, for his "proving-alone being invalid" has actually proved valid his thesis that "proof cannot be proved alone.” All this self-demise reenacts the self-liar who self-demolishes by self-lying.

To repeat, the joke goes this liar paradox way. Taken as valid, his proof is invalid; taken as invalid, it is valid, exactly as "I am a liar" that is invalid when taken valid, and is valid when taken invalid. Gödel thus repeats liar paradox in self-contradiction. Such logical mess should never have happened in logical consistency of mathematics, but precise mathematics calculates into self-demise, as self-liar does.

Naturally, the liar paradox in mathematical logic at the base of Western thinking spreads to its philosophy all-thinking universal, in three ways. First, the pursuit of knowledge that describes philosophy rehashes the liar paradox. As our knowledge increases, the circle of knowledge expands, and its circumference contacting noknowledge widens. "Knowledge" here is taken to include deliberation, systematization, criticism, and the like. In this wide active sense, philosophy is a pursuit par excellence of knowledge. So, increasing knowledge increases contacts with no-knowledge.

Thus, the more philosophy knows, the less it knows, till it knows everything about nothing, to wit, knowing so much into not-knowing. Its pursuit of knowledge destroys itself, as "I am a liar" destroys the liar. Philosophy consists in stamping out no-knowledge, to result in no-knowledge all over in it, as self-liar establishes the liar into no-self. Ironically, it is the pursuit to expand knowledge that meets its own demolition. This "irony" is the liar paradox self-corroding, as the constitutive "atom of philosophy" (Sorensen, 2003). By saying that, as prime numbers are basic atoms to mathematics, so paradoxes are basic atoms to philosophy.

Secondly, Socrates claiming to know nothing was said to be "the wisest of men"; the wisest know-nothing does as self-liar does, self-demolishing in self-building. He then realized that he alone knows he knows-not, to end up touting "Know yourself!" But we cannot self-know as we cannot finish self-describing, as we cannot self-lie. Socrates vainly appeals to one "cannot" to resolve another "cannot," using an impossibility to resolve the impossible liar-paradox.

Thirdly, Kant's critical philosophy is a Copernican self-revolution in self-critiques. But self-criticism cannot finish; Kant must criticize his criticism, ad infinitum. Kant's critical philosophy is as impossible as self-description is. Kant falls in Socratic quicksand of self-knowledge self-sucking, as self-liar self-collapsing. Thus, as knowing filled with no-knowing, self-knowing the quagmire, and self-criticizing ever unfinished, philosophy amounts to self-liar, paradoxically self-corroding. 
Sorensen is correct, then, in announcing "paradoxes” as the basic building blocks of philosophy, and so naturally he compiled a collection of paradoxes as the history of Western philosophy (Sorensen, 2003)! Sadly, this book is more sketchy than deep-probing; it especially rough-treats "paradox" itself so central to the book and to philosophy. Still, even Sorensen never appreciates how the self-liar paradox destroying reasoning itself from its inside, as the paradox corrodes itself. Corrosion is atomic explosion by atomic fission (inter-demolishing) in atomic fusion (inter-composing). And so, Sorensen casually thinks that reasoning would "solve" the paradoxdilemma, never realizing how paradox self-destroys to destroy reasoning itself. He is all too cavalier on the radical seriousness of the crisis of paradox

As a result, Sorensen misses two devastating points in his correct claim. One, he misses that all paradoxes are variations of the liar paradox, and so all philosophy is infested with the self-liar paradox destroying all philosophy from inside. Therefore, two, philosophy is all-unable to "solve” the liar paradox, for philosophy is reasoning, and the liar paradox undermines reasoning from inside. "Wow! This is serious indeed if paradoxes are the atoms of philosophy.” Sadly, Sorensen has no convincing way out of this devastating paradox-dilemma, as he keeps missing its radical seriousness.

All in all, both Gödel and Sorensen show us, all unawares, that all basic necessary reasoning, mathematical and philosophical, self-destroys, as it is infected with the liar paradox at its core. In general, whatever one thinks and expresses involves its negation in an "I am a liar" way, for all assertions are intelligible in light of their negations tacitly understood, unexpressed. All assertions are then both internally affirmative and negative, to invite the self-liar paradox. Thus it is that the principles of thinking in all logic and its philosophy are infested with the self-liar paradox self-corroding.

Sorensen simply went into the history of Western philosophy as a history of paradox, never bothering to look into how devastating the situation is, now that he boldly declared paradoxes as "atoms" of philosophy; atoms of paradoxes are atom-bombs to explode philosophy from inside. Internal inter-opposition of the paradox internally decomposes philosophy (para-) as it composes philosophy (-dox), a vast crisis Sorensen correctly proposed and tragically missed.

Of course, the crisis of paradox pervades all thinking, not limited to Western thinking, but it is a major crisis in the West where serious reasoning is cherished, taking "paradoxes" as its constitutive "atoms" to make its major crisis of self-destruction. Other culture such as China never takes serious reasoning seriously, and so paradoxes are not their thinking-atoms.

Therefore, China can brush away the poison of paradox by toying with it (as Name logicians do) or playing with it (as Taoist Chuang Tzu does). Such toying and playing has a “Tao Pivot 道樞,” Chuang Tzu said (2/3031 ), the reason-Hinge of the Way of things, turning freely as things change freely. It is musical beauty homo-cosmic. For resolution of its paradox crisis, the West's conceptual thinking does well to look to China in playful body-reasoning. To this theme we now turn.

\subsection{Three: How to Deal with the Liar Paradox}

Let us first sum up the crisis we have reached so far, before proposing its resolution in musical beauty. "I am a liar” turns invalid when affirmed, and turns valid when denied. Such is an internal inter-turning into opposites, to logically devastate "I am a liar" itself, to devastate reasoning; reasoning devastates itself paradoxically, in suicide. "I am liar” has been found to fill our days (Section 1) and our thinking (Section 2). Such is elucidated so far.

The West is warned of its self-devastation. Its central "critical Socratism” (Marcel) self-decomposes; the wisest of men Socrates knows nothing, knowing to claim not-knowing, to undermine "reasoning almighty," as self-liar self-undermines. Socrates died by his unjust society because of his own liar paradox internally self-devastating. Resolution of self-dissolution of reasoning can then never come from reasoning self-dissolving. Instead, reasoning must be played with.

Literary beauty can turn "I am a liar" to revel in, singing the world-as-music with the liar paradox as its dissonant rhythm. A criminal now turns into our passionate hero in Les Miserables; our despised and pitied Idiot turns into our ideal, thanks to Dostoevsky. People's revolution from tyranny turns back to oppression of people under the Pig our Tyrant in Animal Farm. The "same" scenes in daily routines now shimmer in ridiculous non-sequiturs in Alice's Wonderland.

Kids can lead us in singing dancing music. Kids are born in music, to be music. Mozart shows us so, but 
every kid sings their music they make that they don’t even understand! They just enjoy singing their music they live! Kids grow in music to grow music, to bounce music to live music. Kids are music that is kids; both are a tautology, even among kids autistic and deaf who do bodily echo the rhythm of music to dance it.

And so, we oppose not reasoning but serious reasoning; "playing with reasoning" reasonably plays with arguments. Reasonable argument-play does not argue (as serious reasoning) but freely plays reasoning, as "play" is reasonable (Wu, 1982, 1998). So many genres of music freely composed have bred various theories. China's Chuang Tzu plays with Name logicians' paradoxes into wonderland homo-cosmic topsy-turvy, created now by an Oxford professor of mathematics, and so more fun than dreary stories of Franz Kafka, who saw the mess but had no mathematics to see its fun-logic.

Pain and injustices often harvest great achievements (Wu, 2014). Unjustly castrated, Ssu-ma Ch’ien 司馬遷 postponed suicide to fulfill his father's last wish, devoting decades to producing his classical History Records 史記. Boethius' Consolation of Philosophy the world's best-longest seller was produced before his unjust execution (Howatson, 1989). They are self-undermining paradox turned life-enriching.

Internal cutthroat in the liar paradox turns around to enrich our life, to breed infinite varieties alive, to contribute to society. Conceptual thinking is clogged up in cul-de-sacs, which yield cornucopia in music, playing with reasoning singing. The odd phrase "reasoning music" is a rhythm of dissonance singing deathly paradox into antiphony celebrating self-demise of reasoning. This is "history" composed by lilting literature singing the world in music homo-cosmic.

The self-liar paradox is now part and parcel of poignant beauty musical. The project dances ringing around the life-roses in daily routines to kid-spread irresistibly. Reveling joins the co-happenings of differences, contraries, and contradictions, called "self-liar paradox in musical revelry" dancing actuality toward novelties, embodied enlivened in toddling children, who do not walk but hop, skip, to jump and get hurt. That is how messy children grow up; we can never get over them.

Kids alive grow tomorrow today, no rhyme yet rhythmic. And we must repeat. Mathematics professor Dodgson at Oxford calculated mathematics into Alice's Wonderland for his dear missy Alice (Carroll, 1971), all liar paradox turned kid-revelry. The liar paradox is "insoluble" because it is not meant to be "solved" but to be played with (Sorensen, 2003). Playing composes music to sing the paradox into dissonant rhythm called history. Literature plays and dissolves. History and literature join playing with the oxymoronic liar paradox, into music historical.

So, our lifeworld sings the music of "literature history" that China claims as life, and "literature history 文史” is China. Such is our resolution of the liar paradox into music in rounds of seasons with Heaven and Earth. We must join with the toddling children to sing the incoherent songs these children keep inventing, so irresistible! This is where all Mozart-Schubert's voluptuous songs originate.

"We must have kid-fun" is our "categorical imperative" of living that no one can resist. We dare anyone in his—no "her" here!—adult "sanity" to try resist kid-joy so noisy so messy! He can either resist, by impossibility, these kids, to perish proudly, or else get disarmed into shouting joy into them, heartfelt. Could we have imagined how the insidious liar paradox undermining thinking could have been turned kid-joys of kid-music so powerfully dissonant? The liar paradox internally opposed is now inter-incoherent in kids' incoherent wobbly growth, shouting their songs no one understands, not even they!

But kids do declare that they wuv-love fafa-flowers and don't wanna be filafila-philosophers. Kids wisely discard serious arguments (philosophy), to flower out into musical beauty. We cannot help but chime in wholeheartedly. All these examples declare the power almighty of musical beauty, belonging exclusively to messy children! These kids playfully dissolve for us adults the liar corrosive paradox into a singing part of their music.

My all-time kid-hero Chuang Tzu in China is here, mere 2300 years young (370-290 BCE) (Chung, 1974). His conclusion of the profound playful Chapter 2 is all vivid soaring, in unity of internal opposites inter-cutting inter-composing, playing with self-referred paradoxes. His conclusion is reproduced in Chapters 17-18 and his whole book. He tells stories concrete fascinating, internally inter-opposed. The "I" is involved in all, to present the subtle self-liar paradox, called “hanging sophistry, sophistry on sophistry 局詭” (2/84), and all this is totally delightful, kid-jumping. All singing story-sophistries chant six times in six irresistible genres, as follows. I am no meticulous commentator, so I may be inaccurate on details of what Chuang Tzu actually said; I also added my interpretations. But I assure you that his main drift of thinking is conveyed completely accurately (Wu, 1990).

One, life vs. death: Lady Beautiful, cherished by a minor border guard her father, is suddenly kidnapped by 
King of the great Chin. Being transferred to a foreign land, the Lady drenched her dress with tears to the neck. But then, the Lady was treated to the royal square bed and grass-fed steak, every day and night. After months, the Lady comes to wonder why she was so sad for being "kidnapped," sorrows all pointless.

The sumptuous palaces of the netherworld may be waiting to treat us royally, more than our small happiness in our tiny world here, and none can refute this stunning possibility. Life and death opposed are related in time; we are soon to be "kidnapped" from this life to that death. And the possible prospect is royally sumptuous. Such daring hypothesis of the brave new world beyond life on which we cling, invigorates us. Sad death-kidnap ends in royal joy; Chuang Tzu turns a liar paradox self-undermining into our happy beyond-life.

Two, awake vs. dreaming: While alive, we know nothing about death; once dead, we cannot come back to tell about it. Thus, considering life vs. death considers known vs. unknown, and we safely guess in joy composed above. But incredibly, we do not know, bewildered, about awake and dreaming, both known interrelated interdifferent.

We dream, dream about dreaming, and tell fortunes about the dreams we dreamed while dreaming. We dread, shed tears, fight, strive, and obey superiors and manage subordinates—all in dreams. We then wake up to forget all that, and live another life. We repeat rounds of odd vicissitudes to live on. Awake and asleep are opposed connected, going from one to the other. "I say you and Confucius are in a dream, and I saying so am also dreaming,” says Chuang Tzu (2/83). I am awake, saying that all people with me are dreaming; awake and dreaming are opposed and related. Unreal-dream penetrates real-awake, all awake asleep. The liar paradox is here selftwisting.

Three, arguing: Arguing is an odd dialogical unity of opposing partners, the one putting the other in the wrong, unaware that it is all futile. All we care for is to win the argument, assuming whoever wins is right; all this is misplaced, he warns. Suppose you win, you may remain wrong. Suppose I win, I may win in the wrong. And we may be both wrong or both right; arguing never decides.

A third party helps not at all. Judging you are right, he is with you, so he may be wrong as you; judging I am right, he is with me, so he may be wrong as I. If he agrees with us both, how could he judge us? If he disagrees with us both, how could he judge us? Thus, futile is this odd unity in opposition called "arguing 辯”; it is another concrete liar paradox, uncertain either way.

Four, right vs. wrong: In the above, we think we know right and wrong. But do we not realize that right or wrong depends on winning or losing in argument? Now that argument is exposed as futile, right and wrong turn futile, going around nowhere. What we need then is to dwell in the realm of no-right no-wrong 無境 (2/92), where things inter-compose, right on wrong, wrong on right.

All this sounds arbitrary, until we watch world history. Brutal battles decide the victor who declares him "right" to condemn the loser as "criminally wrong." Right and wrong are bubbles of self-liar teetering one side and then other side. We must dwell both, righting "right," wronging "wrong," Chuang Tzu says (2/33), to turn self-liar into happy balancing.

Five, penumbra vs. umbra: All the above relies on "dependence” and so Chuang Tzu goes into it. Umbra the shadow exists dependent on something of which it is a shadow; penumbra exists dependent on umbra on which it is a penumbra. Such is self-liar flip-flopping. Chuang Tzu overhears penumbra surprisingly deanding umbra its rationale of existence as a dependent existence, without self-decision.

Umbra brushes off the challenge with rhetorical questions leading the hearer penumbra into uncertainty. Umbra asks, "Do I exist in my dependence? Does what I depend on exist in its dependence? Is my dependence that of snake's skin or cicada's wings? How could anyone know what makes all this exist?”

Does snake's skin depend on the snake to exist? Or does the snake depend on its skin? Doesn't each survive in the other? Does the cicada survive thanks to its wings, or wings exist thanks to depending on cicada? Isn't the very "dependence" interdependent? Look at yourself depending on me to exist, as I exist depending on the thing of which I am a shadow. We dependent on the other are actually what make that other to exist by depending on us, as the shadow shadows forth that thing, as the penumbra describes the umbra to make umbra exist. Such inter-cancelling inter-dependence is the liar paradox.

Six, "I" dreaming a butterfly: Dependence, uncertainty on right and wrong, dispute, awake and dreaming, and life and death, are all summed up in Chuang Tzu dreaming to be a butterfly fluttering between life and death. Last night, I Chuang Chou dreamed to be a butterfly, assured, fluttering. I awoke, and I am sure I am a man. But then, I am not sure. Am I the man having dreamed butterfly? Am I the butterfly now dreaming me the man?

Twist and turn as I may, I cannot decide which is what, each case being as natural and convincing as the other, 
as a self-liar twists. "I cannot decide" is my actual situation. I am fluttering as butterfly between dreaming and awakening, certainty and uncertainty, and life and death. Still there must be distinction between all opposites that I flutter. I might as well $d$ well in such distinctions inter-changing. Dwelling is at home; inter-changes transmute. To dwell at home in dynamic inter-changes is living restful restless, turning the liar paradox into singing music of unity alive.

All these stories appear in rapid succession; all involve "I," all playing with the liar paradox. In all this storyblizzard, corrosive "I am a liar" turns into lilting music totally playful. With the very toxic liar paradox as means, Chuang Tzu fabulously covers the lifeworld, in comprehensive beauty that sings life and death, dreaming and awakening, right and wrong, and real and unreal, all in sizzling "hanging sophistry of sophistry over sophistry" of self-liar, shouting around, jumping alive, never finished.

All this chanting music plays with arguing, romping reasoning, devil may care. All this is worked up only by the naughty "perfect brats" none can repress, none can resist. In fact, I must confess. All such irrepressible pattern of playing seriously not-seriously is so irresistible that, however clumsily, the present essay has been following it, guided by it to ineptly rhyme with it so subtle. All such self-liar paradox bewildering is a fabulous hanging sophistry of self-liar to play with, to bang around to enter life-oxymoronic revelry all comic all cosmic, in all kid-delight.

\section{Tying}

While the scientist is busy solving problems, even by pathological investigation to find problems to solve them, the philosopher keeps trying to find new problems to ponder on, seldom in order to solve them. As the philosopher finds [a] more serious and [b] more numerous problems, more excited the philosopher turns. [a] The worst problem the philosopher has found is one that devastates reasoning the essence of philosophy, by internal inter-opposition of a statement; it is the liar paradox.

And then, [b] the philosopher tries to turn "one rational statement" that poisons philosophy into "any statement," to find how all statements exhibit the liar paradox, as Gödel showed at the base of mathematical logic, alone toward not-alone, which rehearses this paradox, to demonstrate how any reasoning is Gödel writ ubiquitous. So, philosophy finds in the liar paradox a problem that is the worst and the most universal.

Reasoning is an individual operation universalized, as Gödel personally proves a theorem for universal application. Philosophy then finds that in this universalizing of individuality lurks the liar paradox, as Gödel unwittingly shows. Thus again the liar paradox is found to be the most [a] serious and the most [b] ubiquitous of the problems in any reasoning. Such is how this essay pursued.

“But, then, hasn't this essay solved (as science does) a problem (liar paradox), after all?” Oh, thanks for your sensitive query, my friend. No, this essay has solved nothing, for the liar paradox is "insoluble"; this essay has instead pondered on its poison and resolved it into dissonance in music. "How did you resolve it?" Playing with it resolved it. "How did you play?" Chuang Tzu the argument-player has showed us how, as presented above.

I confessed that, however clumsily, this essay has followed Chuang Tzu the kid, to ponder on the liar paradox, to play with its poison, to resolve it with its poison intact into (dissonance in) musical beauty kid-cosmic, casual joyous. "Poison into joy" is the kid-way to play with liar-paradox. Thus, as science solves problems by manipulating them, philosophy ponders on paradoxes to resolve them into dissonant music, by playing with paradox-insoluble, singing to charm an argument-snake with its poison. Chuang Tzu the kid plays with self-twisty reasoning-snake, charming it sinuous poisonous by singing it as music.

His soft kid-power draws even the sinister liar-snake into dancing music, as the tradition of China claims that kids handle snakes not getting hurt. Since 1990, I have been watching Joseph S. Nye's "soft power" that attracts, not coerce (hard power). Its similarity to Taoism is uncanny, but Taoism is never mentioned. Now he combines it with "hard power" into "smart power," by "contextual intelligence" for "coercion, payment, and persuasion" to move others. I am glad he and I are in similar wavelengths, but we differ. I put "hard power" of clinical therapy to treat as a means to perception spearheaded by listening. Nye stresses "hard power" in international politics (Nye, 2009). Kid's innocence is simply invincible joy-full. Amazingly, kids are not sad; they just wail it out of their viscera and continue to play in joys to draw us in. Play is their soul joy and power. Kid's play charms snake-sorrows into life-joys. Actually, the liar-snake self-poisons to death to spread death to all others. But introducing this complexity would stretch the metaphor beyond its breaking point.

"Life is a white colt passing a door-crack"; Chuang Tzu’s (22/39) original Chinese has been singing for mil- 
lennia till today beyond today. “Ideas won’t keep,” said Whitehead (1954), and this idea of "ideas won’t keep” has been keeping Platonically forever fresh. Dynamite was snake-charmed into Nobel Prizes. Atom-bombs are now snake-dancing peaceful energies with their radioactive poison intact. These examples are the liar paradox, inter-opposed inside, turned dancing delightful.

Broken toys played, nuclear energy for peace, and Nobel Prizes, all sing the music of living in three turns. [a] They are all self-liar turned on the self, [b] itself turned snake-around [c] to turn musical. To begin, [a] toys broken unplayable are [b] turned around played in kid-ingenuity, as [a] self-liar self negating [b] turned around all-positive. Toys broken played parallel self-liar turned around positive.

And we adults [a] invented nuclear energy as weaponry, humans killing humans as self-liar turned on the self. [b] Then the self-liar killer-energy turns around, to use as power for our welfare. Finally, [a] Mr. Nobel the death merchant, human turned on human as self-liar turned on the self, [b] turns around into instituting Nobel Prizes for world peace. And then [c] toys broken and played, killer-energy for peace, and Mr. death-Nobel for Nobel Prizes for peace, all turn musical. Musical pull of play and peace turns these self-liar examples around into singing the world. Such is how music snake-charms the liar paradox our inner poison into living whistling.

"What are such turning and turning-around? What's going on here? Please explain.” Let me try. "I am a liar" self-lies to self-deny. Self-denial is self-referred inconsistency that is instability, to inevitably turn; "in" repeated here is negation that moves things. Self-liar turning is inner opposition to corrode. But then, turning keeps turning to turn around, to turn corrosion into benefit. This further turning-around charms, in music, the paradoxsnake to sing. Such is how turnings happen. As the paradox-corrosion is ubiquitous, so charmed-snake dances to benefit all, in Yin-Yang turning of corrosion into benefit, and charming music prevents the reverse turning of self-liar corrosion to keep the turning to turn-around into benefit.

The self-liar's Yin poison is its inner inter-kill. Lao Tzu (58) turns its one-sided Yin-poison around into YinYang balance, by chanting "O woe where weal leans! O weal where woe lurks!” It is musical beauty yoking Yin-inter-kill to Yang-inter-birth chanting cautious optimism of weal leaning out of woe, and then cautions on woe lurking out of weal, and thereby the chant turns Yin-woe around into Yang-weal.

Music thus chants the liar paradox self-undermining into our ecological joy inter-thriving. Each of us wins! How exciting! We must snake-charm the toxic liar paradox into singing the world. I have tried, dear reader, to sing the music of reasoning on music beauty that snake-charms the self-liar poison into singing all life all reasoning. Let us sing together music almighty into world concord, happily ever after!

\section{References}

Arendt, H. (1963). Eichmann in Jerusalem: A Report on the Banality of Evil. NY: Penguin.

Barrett, W. (1956). Zen Buddhism: Selected Writings of D. T. Suzuki. Garden City, NY: Doubleday.

Carroll, L. (1971). Alice in Wonderland (2nd Edition). NY: W. W. Norton.

Chung, C. (1974). Chuang Zu. Tokyo: Tokyo Publishers.

Dawson Jr., J. W. (1997). Logical Dilemmas: The Life and Work of Kurt Gödel. Wellesley, MA: A K Peters.

Howatson, M. C. (1989). On Boethius (pp. 90-91). The Oxford Companion to Classical Literature.

Kline, M. (1980). Mathematics: The Loss of Certainty. NY: Barnes \& Noble.

Nye, J. S. (2009). International Politics. Foreign Affairs, July/August, 160-163.

Scott, R. B. Y. (1965). Proverbs; Ecclesiastes. The Anchor Bible, 18, 209.

Sorensen, R. (2003). A Brief History of the Paradox (pp. 194-196). Oxford: Oxford University Press.

Whitehead, A. F. (1954). Dialogues of Alfred North Whitehead (p. 250). Boston: David R. Godine.

Wu, K.-M. (1982). Chuang Tzu: World Philosopher at Play. NY: Crossroads and Chico.

Wu, K.-M. (1990). The Butterfly as Companion (pp. 113-277). Albany, NY: State University of New York Press.

Wu, K.-M. (1998). On the "Logic" of Togetherness: A Cultural Hermeneutic (pp. 150-293). Leiden: Brill.

Wu, K.-M. (2012). Nonsense: Cultural Mediations on the Beyond. NY: Nova Science.

Wu, K.-M. (2014). In Praise of Pain. Global Journal of Human Social Sciences, July. 